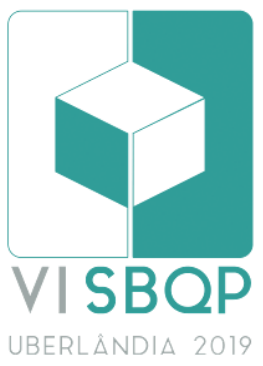

\title{
ANÁLISE DE UMA PRÁTICA DE ARQUITETURA ALTERNATIVA PARA DEMANDAS POPULARES
}

\author{
SA, Lorrainy Cristina Lage \\ Centro Universitário do Leste de Minas - UNILESTE, e-mail: lorrainycls@gmail.com \\ ÁVILA, Vinícius Martins \\ Centro Universitário do Leste de Minas - UNILESTE, e-mail: vnc.avila@gmail.com
}

\begin{abstract}
RESUMO
A prática de arquitetura utilizada pelos arquitetos e urbanistas da Região Metropolitana do Vale do Aço - RMVA não atende de forma eficaz as demandas populares, que acabam optando por construir sem o auxílio de um profissional especializado. Dessa forma, o objetivo do estudo foi estabelecer uma prática de arquitetura alternativa à convencional, que consiga atender as demandas populares, e que diminua o distanciamento existente entre esse público e o arquiteto e urbanista. Como metodologia, foi realizada uma pesquisa experimental onde foram elaborados projetos arquitetônicos, para o público popular da RMVA, utilizando como base o método sistematizado pelo arquiteto argentino Rodolfo Livingston, a fim de avaliar a sua eficiência e fazer adaptações. Dessa maneira, conclui-se que os atendimentos realizados serviram como um meio para a construção de uma metodologia que poderá orientar os arquitetos e urbanistas no desenvolvimento de projeto para as demandas populares. Essa nova prática de arquitetura possibilitará que esse público tenha acesso a um projeto arquitetônico, além de promover uma aproximação entre os agentes envolvidos no processo.
\end{abstract}

Palavras-chave: Prática de arquitetura, Método, Demandas Populares, RMVA.

\begin{abstract}
The architectural practice used by the architects and urban planners of the Metropolitan Region of the Vale do Aço-RMVA does not meet effectively the popular demands, which they choose to build without the assistance of a specialized professional. In this way, the objective of the study was to establish an alternative architectural practice to the conventional one, that is able to attend to the popular demands, and that diminishes the existing distance between this public and the architect and urbanist. As a methodology, an experimental research was carried out where architectural projects were elaborated for the popular public of the RMVA, using as basis the method systematized by the Argentine architect Rodolfo Livingston, in order to evaluate its efficiency and make adaptations. In this way, it can be concluded that the services provided served as a medium for the construction of a methodology that could guide the architects and urban planners in the development of the project for the popular demands. This new architecture practice will allow this public to have access to an architectural project, as well as to promote an approximation among the agents involved in the process.
\end{abstract}

Keywords: Architecture Practice, Method, Popular Demands, RMVA.

\section{INTRODUÇÃO}

Segundo pesquisa realizada pelo Conselho de Arquitetura e Urbanismo do Brasil - CAU/BR (CAU, 2016), da população economicamente ativa do Brasil que já construiu ou reformou, $85,40 \%$ não contratou um profissional especializado para realizar a construção. Além disso, $49 \%$ dos entrevistados pertenciam a classe C, classe social que em 2015 contava com 57,1\% do total da população brasileira, de acordo com o Instituto Brasileiro de Geografia e

SA, L. C. L.; ÁVILA, V. M. Análise de uma prática de arquitetura alternativa para demandas populares. In: SIMPÓSIO BRASILEIRO DE QUALIDADE DO PROJETO NO AMBIENTE CONSTRUÍDO, 6., 2019, Uberlândia. Anais... Uberlândia: PPGAU/FAUeD/UFU, 2019. P. 269-281. DOI https://doi.org/10.14393/sbqp19027. 
Estatística - IBGE (IBGE, 2015). Ao analisar esses dados seria possível presumir que faltam arquitetos no mercado de trabalho para atender as demandas populares, porém não é isso que acontece já que segundo o CAU (2016), só em 2016 tinham 143.401 profissionais em atividade no país, o que equivale 1.437 habitantes para cada arquiteto.

Em um estudo realizado na Região Metropolitana do Vale do Aço (RMVA), Sa e Ávila (2018), concluíram que um dos fatores que causam o distanciamento entre o arquiteto e o público popular é a ineficiente da prática de arquitetura convencional em atender as demandas populares. Isso ocorre devido a incompatibilidade dos métodos de construção utilizados pelo profissional de arquitetura e por essas pessoas.

Diante desse cenário, seria possível presumir que tanto o arquiteto quanto o público popular poderiam se beneficiar da difusão de uma prática que fosse compatível com o método de construção utilizado por essas pessoas, e que fosse mais próximo da realidade vivida por elas. Portanto o objetivo do estudo é estabelecer uma prática de arquitetura que atenda as demandas populares da RMVA, buscando diminuir o distanciamento existente entre esse público e o arquiteto e urbanista. Dessa forma, espera-se reduzir o índice de autoconstrução de moradias, já que esse tipo de produção, sem o acompanhamento de um profissional especializado, pode trazer prejuízos financeiros para os moradores, resultar em ambientes sem qualidade espacial e causar reflexos negativos para a cidade.

O termo Demandas Populares, de acordo com Kapp, Nogueira e Baltazar (2009), refere-se a demandas relacionadas a habitação ou pequena instalação comercial, oriunda de pessoas que possuem recursos financeiros, mesmo que relativamente limitado, para realizar uma construção, e que não pertencem ao mesmo círculo social que a elite. Trata-se, portanto, de um público que integra as camadas intermediárias da sociedade, e que nesse estudo fará referência às demandas da classe C.

\section{REVISÃO BIBLIOGRÁFICA}

Nos períodos anteriores ao Renascimento, o ensino de arquitetura ocorria dentro dos canteiros de obras, de forma que o aprendiz só se tornava um profissional se conseguisse executar seu ofício com sucesso. Posteriormente com a institucionalização da educação, a experimentação prática dentro de canteiros de obras foi deixada de lado, de forma que o ensino ficou voltado para a parte teórica da profissão, com ênfase na composição estética e formal. Atualmente as escolas de arquitetura permanecem fora dos canteiros de obras, priorizando disciplinas de elaboração de projetos para médio e grande porte e grandes intervenções urbanas. Com isso, "o profissional formase um especialista em desenhos, modelos e apresentação de projetos, mas pouco conhece sobre materiais e tecnologias construtivas" (NOGUEIRA, 2010, p.162).

Indo na contramão da produção formal de construções está a autoprodução de moradias que, segundo Sa e Ávila (2018), trata-se de um processo em que os próprios usuários realizam e tomam as decisões com relação a obra. Todo o conhecimento técnico empregado é proveniente apenas da experiência da mão-de-obra e das informações obtidas em lojas de materiais de construção, internet e com conhecidos. Além disso, esse tipo de produção tido como 
informal permite que a moradia seja construída aos poucos, conforme a disponibilidade de recursos financeiros e dos aspectos que são tidos como prioridade pela família. De acordo com Nogueira (2013), como a prática de arquitetura convencional não vai de encontro com os anseios e necessidades do público popular, que demanda por pequenas ampliações e resoluções de defeitos construtivos, essas pessoas acabam enxergando o arquiteto como um profissional de elite, cujo trabalho é apenas projetar mansões e interferir negativamente em uma construção.

Diante desse cenário, Nogueira (2013) aponta que o arquiteto poderia trabalhar em prol das demandas populares, porém falta experiencia e conhecimento construtivo e técnico na área. Como consequência, o público popular continua tendo pouco acesso a um profissional especializado, fazendo com que suas moradias carreguem diversos problemas e deficiências, que poderiam ser evitadas se esses autoprodutores tivessem uma assistência técnica.

Na Região Metropolitana do Vale do Aço, Sa e Ávila (2018) realizaram um estudo com as demandas populares e escritórios de arquitetura com 0 objetivo de descobrir os fatores que causam o distanciamento entre esses indivíduos e o arquiteto. Ao analisar o público popular, os autores perceberam que o fator determinante na autoprodução é a disponibilidade de recursos financeiros. Além disso, notaram que a mão-de-obra empregada é quase sempre familiar e não existe a utilização de um esboço ou planta, as decisões com relação aos espaços vão sendo tomadas no decorrer da construção, tratando-se, portanto, de um processo aberto. Também concluíram que algumas demandas populares não necessitam de projeto arquitetônico, já que consultorias e visitas em obra já solucionariam os problemas.

Com relação aos profissionais de arquitetura, Sa e Ávila (2018), compreenderam que a prática de arquitetura é pouco flexível, já que o usuário não tem a possibilidade de contratar e pagar por apenas determinadas etapas da metodologia projetual. Os clientes possuem pouca participação no processo de criação, então algumas demandas acabam sendo negligenciadas pelo profissional, fazendo com que os projetos nem sempre sejam executados conforme foram elaborados. Além disso, perceberam que poucos escritórios prestam serviços de execução de obra e consultorias. Dessa forma, o que ficou evidente foi que a prática de arquitetura convencional não é eficiente para atender as demandas do público popular, por se tratar de "um choque entre dois modi operandi diferentes" (NOGUEIRA, 2010, p.167).

\section{METODOLOGIA}

Para desenvolver a prática de arquitetura adaptada a realidade das demandas populares da RMVA, foi realizada uma pesquisa experimental com o intuito de avaliar a eficiência e realizar adaptações em uma metodologia projetual pré-existente. Para isso, foram selecionadas cinco famílias que se enquadram na classificação de demandas populares e que estavam iniciando uma construção sem assistência técnica especializada. A metodologia utilizada como base para a realização dessa pesquisa foi o método sistematizado pelo arquiteto argentino Rodolfo Livingston, e que já foi 
testado e adaptado por Nogueira (2010) na Região Metropolitana de Belo Horizonte.

\section{PRIMEIRA FASE}

1. Pré entrevista

2. Entrevista

3. O lugar, o cliente (levantamento)

SEGUNDAFASE

4. Apresentação dos projetos

5. Devolução e ajuste final

6. Manual de instrução
Coleta de dados

Elaboração de projeto

Figura 1- Etapas do método

Fonte: Adaptado de Nogueira (2010)

O método, caracterizado como participativo, objetiva viabilizar o diálogo e a troca de informações entre o arquiteto e o cliente. Além disso, busca reduzir as formalidades projetuais que dificultam o entendimento do projeto pelo usuário e pela mão-de-obra, durante a execução da construção. O processo é dividido em seis etapas agrupadas em duas fases de projeto. As três primeiras etapas são destinadas a coleta de informações, que serão utilizadas nas etapas de elaboração de projeto (Figura 1).

Pré entrevista: A pré entrevista é a primeira conversa que ocorre entre arquiteto e cliente, e tem como objetivo inicial compreender quais são as demandas dos usuários e porque eles estão procurando pelo serviço de um profissional de arquitetura. Após firmado o acordo de realização do projeto entre o arquiteto e o cliente pode-se dar continuidade às etapas.

Entrevista: Na entrevista o profissional deve aplicar alguns exercícios aos usuários, com o objetivo de conhece-los mais a fundo e identificar suas necessidades. O Projeto do Cliente tem como objetivo compreender qual é a demanda e quais são as ideias da família para a construção. Para isso os usuários devem fazer croquis/plantas do que desejam realizar e apresentar esses desenhos ao arquiteto (Figura 2).

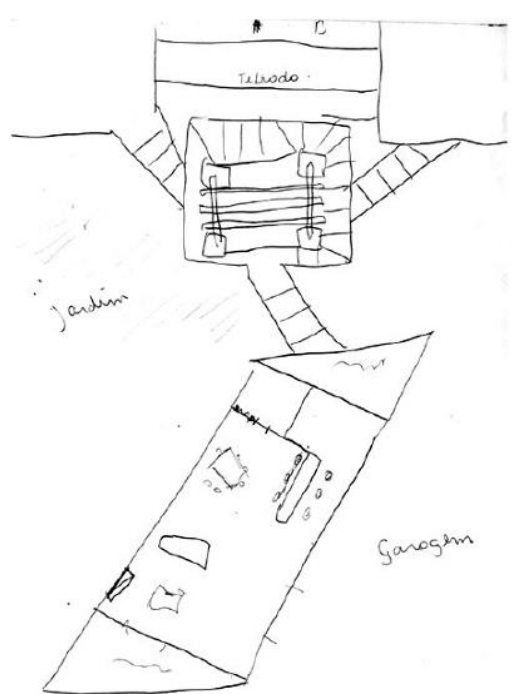

Figura 2 - Projeto do Cliente

Fonte: Nogueira (2010) 
O exercício Jogo de Acusações tem como objetivo levantar o que cada morador mais gosta e menos gosta no local em que ele vive, podendo ser característica espacial da residência, do bairro, da rua e/ou relacionadas a comportamento de outros moradores. Por último, o Diagrama dos Globos tem como objetivo tentar flexibilizar os futuros espaços que estão sendo planejados. Para isso os usuários, juntamente com o arquiteto, devem escrever os nomes dos ambientes numa folha de papel e unir, utilizando círculos, os espaços que podem ser agregados e que possuem a mesma funcionalidade.

O lugar, o cliente: Nessa etapa o arquiteto deve visitar o local a ser reformado ou construído e fazer as devidas observações e medições. Inicialmente é necessário medir as ruas e verificar o sentido de circulação, desenhar as divisas do lote e árvores existentes no entorno. Se for um projeto de reforma, o profissional deve elaborar um croqui do espaço com todos os mobiliários existentes, tirar as medidas gerais e depois as parciais. Posteriormente, deve-se verificar as condições físicas e estruturais do imóvel, fazer registros fotográficos e, se necessário, desenhar cortes evidenciando alturas diferentes.

Elaboração e apresentação das Opções de projeto: $O$ método recomenda que sejam elaborados e apresentados aos clientes diferentes opções de arranjos espaciais, para que os usuários consigam analisar e escolher a opção que mais atende as suas demandas.

Como uma das características da metodologia e se aproximar da realidade desse público, os desenhos a serem apresentados devem possuir uma linguagem simplificada e sem formalidades projetuais, facilitando a compreensão dessas pessoas do que está sendo proposto. Por isso os desenhos (plantas e perspectivas) devem ser realizados a mão livre, com layout, utilizando a escala 1/100, sem nenhum tipo de simbologias e convenções técnicas, com textos escritos por extenso e com letras grandes (Figura 3).

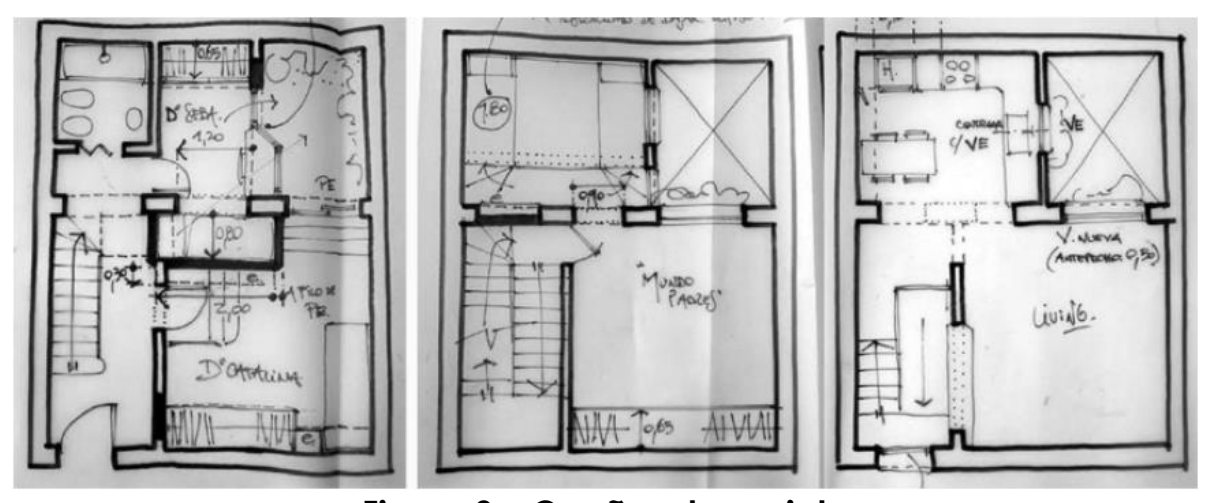

Figura 3 - Opções de projeto

Fonte: Nogueira (2010)

Devolução e ajuste final: Ełapa em que o cliente dá o feedback ao arquiteto sobre as opções de projeto apresentadas. Após análise, os usuários podem solicitar alterações e até mesmo propor uma nova opção com base nas que foram entregues a eles na etapa anterior. Com a definição do projeto escolhido pode-se dar início a próxima etapa que é a do Manual de instrução

Manual de Instrução: O objetivo do manual é fornecer aos usuários informações e instruções básicas para a realização de uma construção, delegando aos construtores e aos moradores a responsabilidade de construir. Isso se aproxima mais da forma que essas pessoas estão habituadas a realizar 
e conduzir uma obra. Para a realização desse manual o método estabelece que sejam elaboradas plantas e cortes mostrando mobiliários, cotas, especificações técnicas, pontos elétricos e hidráulicos e abertura de portas e janelas. Elevação com propostas de cores, detalhes de elementos construtivos (quando necessário), e perspectivas mostrando soluções espaciais específicas (quando necessário). A partir desses desenhos básicos o cliente pode ou não solicitar mais informações.

\section{RESULTADOS E DISCUSSÃO}

Inicialmente foram realizados três atendimentos para que o método e seus procedimentos fossem avaliados. Então, com base nas aplicações da metodologia, foi possível fazer as seguintes observações (Tabela 1):

Tabela 1 - Aplicação do método

\begin{tabular}{|c|c|c|c|c|}
\hline Ełapas & Procedimentos & $\begin{array}{l}\text { Família } 1 \\
\text { (reforma) }\end{array}$ & $\begin{array}{c}\text { Família } 2 \\
\text { (construção } \\
\text { nova) } \\
\end{array}$ & $\begin{array}{l}\text { Família } 3 \\
\text { (reforma) }\end{array}$ \\
\hline \multirow{3}{*}{ Entrevista } & Projeto do Cliente & Eficiente & Eficiente & Eficiente \\
\hline & Jogo de Acusações & Pouco eficiente & Eficiente & Eficiente \\
\hline & Diagrama de Globos & Ineficiente & Ineficiente & Ineficiente \\
\hline O lugar, o cliente & $\begin{array}{l}\text { Diretrizes } \\
\text { Levantamento }\end{array}$ & Pouco eficiente & Pouco eficiente & Pouco eficiente \\
\hline \multirow{4}{*}{$\begin{array}{c}\text { Elaboração das } \\
\text { opçōes de } \\
\text { projeto }\end{array}$} & $\begin{array}{l}\text { Diferentes opções de } \\
\text { projeto }\end{array}$ & Eficiente & Eficiente & Eficiente \\
\hline & $\begin{array}{l}\text { Linguagem simples, } \\
\text { sem termos técnicos }\end{array}$ & Eficiente & Eficiente & Eficiente \\
\hline & Plantas a mão livre & Pouco eficiente & Pouco eficiente & Pouco eficiente \\
\hline & $\begin{array}{l}\text { Perspectivas a mão } \\
\text { livre }\end{array}$ & Ineficiente & Ineficiente & Ineficiente \\
\hline $\begin{array}{c}\text { Devolução e } \\
\text { ajuste final }\end{array}$ & & Eficiente & Eficiente & Eficiente \\
\hline \multirow{4}{*}{$\begin{array}{l}\text { Manual de } \\
\text { instrução }\end{array}$} & $\begin{array}{l}\text { Uma planta } \\
\text { contendo todas as } \\
\text { informações }\end{array}$ & Pouco eficiente & Pouco eficiente & Pouco eficiente \\
\hline & Cortes & Ineficiente & Eficiente & Ineficiente \\
\hline & Elevações & Ineficiente & Eficiente & Ineficiente \\
\hline & \begin{tabular}{|l} 
Perspectivas e \\
detalhes construtivos
\end{tabular} & Eficiente & Eficiente & Eficiente \\
\hline
\end{tabular}

Fonte: Os autores (2019)

Na etapa da entrevista os dois exercícios mais eficientes foram o Projeto do Cliente e o Jogo de Acusações, pois possibilitaram uma coleta de informações consideravelmente consistente. Já o Diagrama de Globos se mostrou ineficiente pois os dados levantados em sua execução já haviam sido relatados nos exercícios anteriores. Durante a etapa O lugar, o cliente foi possivel perceber a ausência de algumas diretrizes que são essenciais para a realização de um levantamento completo e que auxilie na elaboração do projeto. 




Figura 4 - Entrevista (Família 3)

Fonte: Os autores (2018)

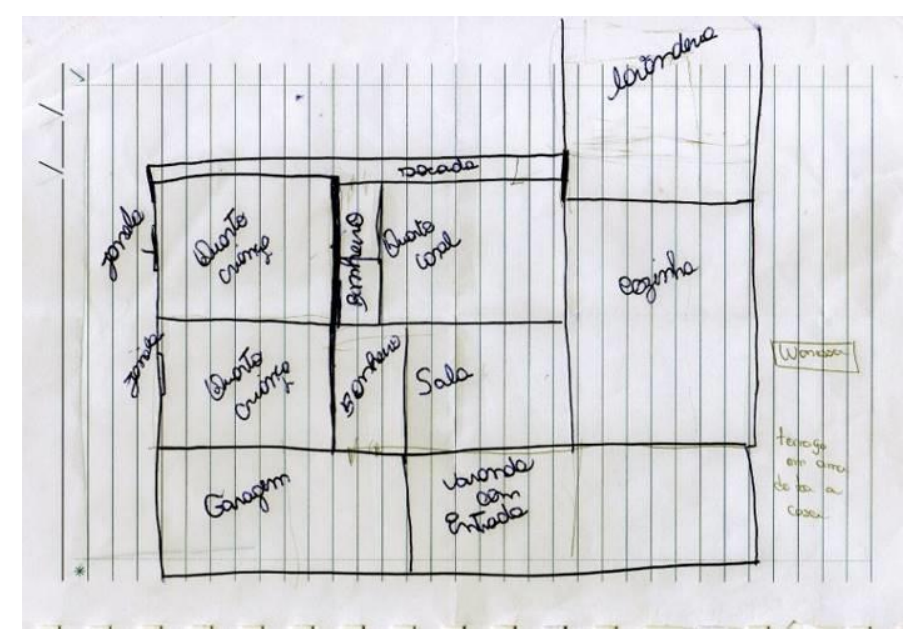

Figura 5 - Projeto do Cliente (Família 2)

Fonte: Os autores (2018)

Já na etapa de Elaboração das opções de projeto foi possível concluir que plantas elaboradas a mão livre são eficientes, porque se aproximam da linguagem que essas pessoas estão habituadas e faz com que sintam liberdade de opinar e fazer intervenções nos desenhos, tornando a etapa mais participativa. Porém a falta de habilidade do arquiteto em desenho a mão pode tornar o processo mais lento, e consequentemente mais caro para o cliente, considerando que o honorário do profissional de arquitetura é calculado por hora trabalhada. Quanto a apresentação de imagens em perspectivas, nos três casos analisados os usuários mostraram dificuldade em entender o que estava sendo proposto a eles. Em dois atendimentos a apresentação de plantas e perspectivas não foi o suficiente para que os clientes entendessem os projetos, sendo necessário utilizar os locais que seriam reformados para ilustrar os projetos. 


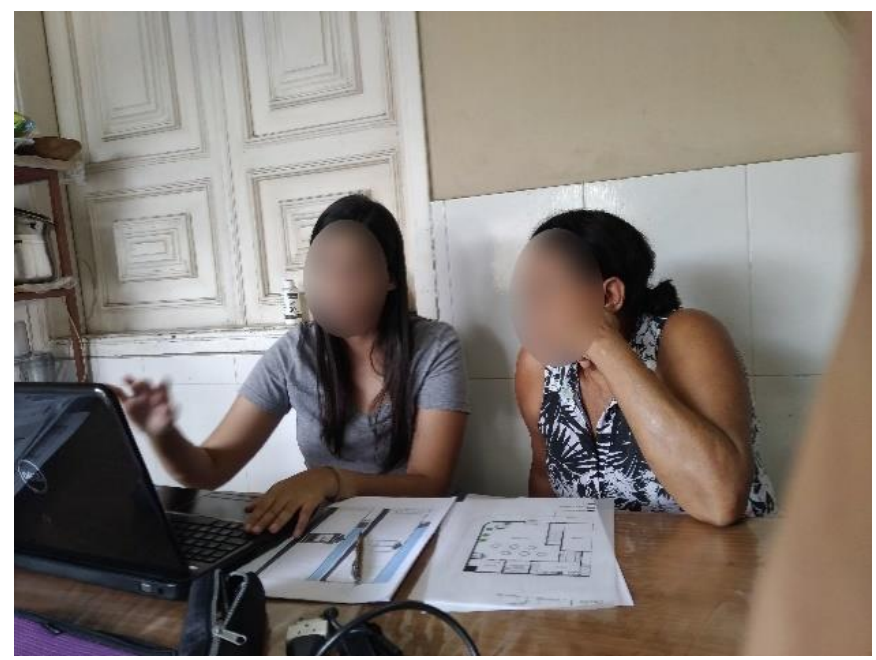

Figura 6 - Apresentação das opções de projeto (Família 1)

Fonte: Os autores (2018)

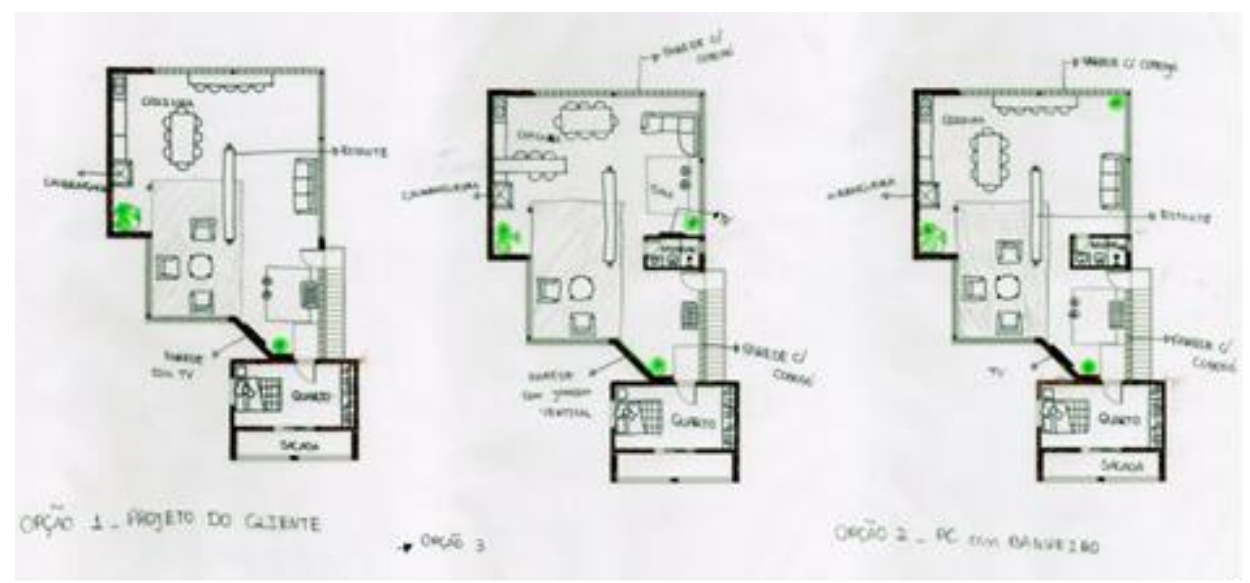

Figura 7 - Opções de projeto (Família 3)

Fonte: Os autores (2018)

Durante a execução do Manual de instrução foi possível notar que os desenhos básicos exigidos nessa etapa funcionam muito bem para demandas de construções novas e de alguns casos de ampliações. Porém para reformas, representações como cortes e elevações nem sempre são eficientes para passar as informações e instruções aos clientes.

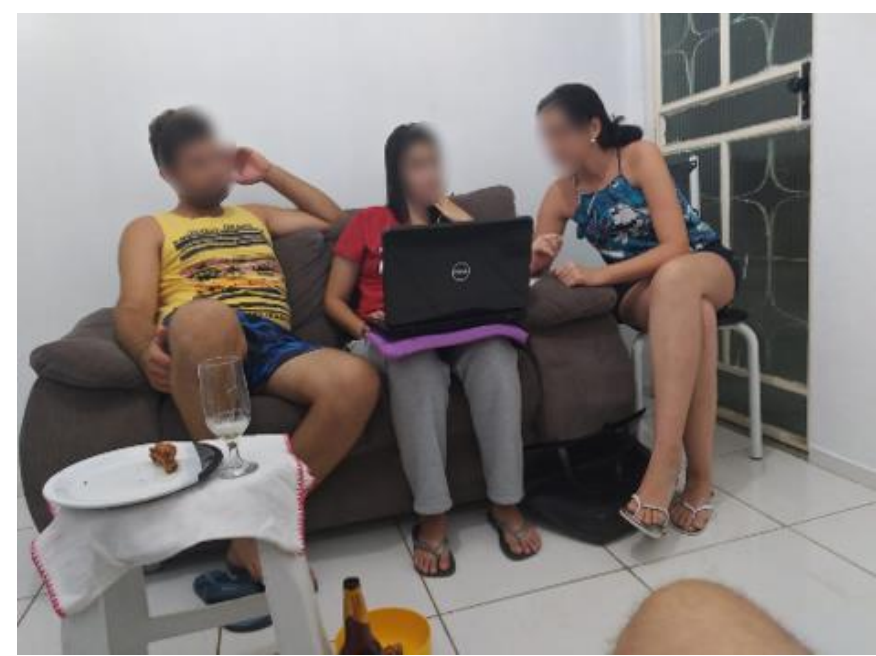

Figura 8 - Reunião para definição do Manual de Instrução (Família 2) 
Após a finalização do processo projetual com as três primeiras famílias, e com base nas análises realizadas em todos os procedimentos, foram propostas adaptações ao método com o objetivo de melhorar seu desempenho no atendimento ao público popular. Na etapa da Entrevista, com a finalidade de enxugar os processos e fazer com que os usuários reflitam sobre a funcionalidade dos espaços almejados, o exercício Diagrama de Globos foi incorporado ao Projeto do Cliente, de forma que durante sua realização o arquiteto questionasse aos usuários quais as atividades poderiam ser realizadas nos ambientes que eles desenharam em seus projetos.

Na etapa seguinte foram adicionadas diretrizes que não estavam previstos na metodologia para a execução do levantamento, mas que são importantes para essa tarefa. Então além de desenhar as árvores e divisas do lote o arquiteto deveria também pontuar os equipamentos urbanos próximos; indicar na planta as instalações elétricas e hidrosanitárias em casos de reformas ou ampliações; além de fotografar deveria indicar na planta o sentido do olhar de cada fotografia para facilitar as análises futuras; fazer análise de conforto ambiente; verificar a pré-existência de um projeto; e fazer levantamento de dados e documentos, como por exemplo a escritura do imóvel e etc.

Para a etapa de Elaboração das opções de projeto ficou estabelecido que o profissional poderia utilizar softwares, como AutoCAD e Sketchup, para a elaboração das plantas e volumetrias, desde que as imagens fossem tratadas a mão livre de forma que a linguagem projetual permanecesse simplificada e que não tivesse o aspecto de projeto pronto e acabado, o que pode intimidar os clientes. Além disso a apresentação desses projetos deveria ocorrer no espaço que seria construído ou reformado, possibilitando que o arquiteto utilizasse o local para ilustrar as propostas.

Para o Manual de Instrução ficou estabelecido que em demandas por reformas e alguns tipos de ampliações seria utilizado, para substituir cortes e elevações, imagens em perspectivas contendo especificações técnicas e cotas, por se tratar de um tipo de representação que tende ser de mais fácil entendimento para o cliente e para a mão-de-obra. Já as plantas deveriam ser separadas por temas e etapas de construção, evitando acumulo de informações em apenas um desenho.

Posteriormente, dessa vez para avaliar a eficiência do método com as adaptações, foram selecionadas outras duas famílias que também se enquadram na classificação de demandas populares, para a elaboração de projetos (Tabela 2). 
Tabela 2 - Aplicação do método adaptado

\begin{tabular}{|c|c|c|c|}
\hline Ełapas & Procedimentos & $\begin{array}{l}\text { Família } 4 \\
\text { (Reforma) }\end{array}$ & $\begin{array}{c}\text { Família } 5 \\
\text { (Ampliação) }\end{array}$ \\
\hline \multirow{2}{*}{ Entrevista } & Projeto do Cliente + D. G & Eficiente & Eficiente \\
\hline & Jogo de Acusações & Eficiente & Eficiente \\
\hline O lugar, o cliente & $\begin{array}{l}\text { Diretrizes Levantamento } \\
\text { completa }\end{array}$ & Eficiente & Eficiente \\
\hline \multirow{4}{*}{$\begin{array}{l}\text { Elaboração das } \\
\text { opçōes de projeto }\end{array}$} & $\begin{array}{l}\text { Diferentes opções de } \\
\text { projeto }\end{array}$ & Eficiente & Eficiente \\
\hline & $\begin{array}{l}\text { Linguagem simples, sem } \\
\text { termos técnicos }\end{array}$ & Eficiente & Eficiente \\
\hline & $\begin{array}{l}\text { Plantas no CAD tradadas a } \\
\text { mão }\end{array}$ & Eficiente & Eficiente \\
\hline & Volumetria 3D no Sketchup & Pouco eficiente & Pouco eficiente \\
\hline $\begin{array}{l}\text { Devolução e } \\
\text { ajuste final }\end{array}$ & & Eficiente & Eficiente \\
\hline \multirow{4}{*}{$\begin{array}{l}\text { Manual de } \\
\text { instrução }\end{array}$} & $\begin{array}{l}\text { Plantas separadas por } \\
\text { temas e etapas de } \\
\text { construção }\end{array}$ & Eficiente & Eficiente \\
\hline & Cortes & Ineficiente & Eficiente \\
\hline & Elevações & Ineficiente & Eficiente \\
\hline & $\begin{array}{l}\text { Perspectivas e detalhes } \\
\text { construtivos com cotas e } \\
\text { especificações técnicas }\end{array}$ & Eficiente & Eficiente \\
\hline
\end{tabular}

Fonte: Os autores (2019)

Na Entrevista a junção do Diagrama de Globos com o Projeto do Cliente foi eficiente, pois além de possibilitar que o arquiteto conhecesse as demandas $e$ os desejos dos usuários para a construção, permitiu que eles refletissem sobre a real necessidade de alguns espaços que eles haviam desenhado. O Jogo de acusações, que não passou por adaptação, continuou se mostrando eficiente. Já na etapa O lugar, o cliente a adição de outras diretrizes ao método, tornou o levantamento e a coleta de informações mais completa e consistente.

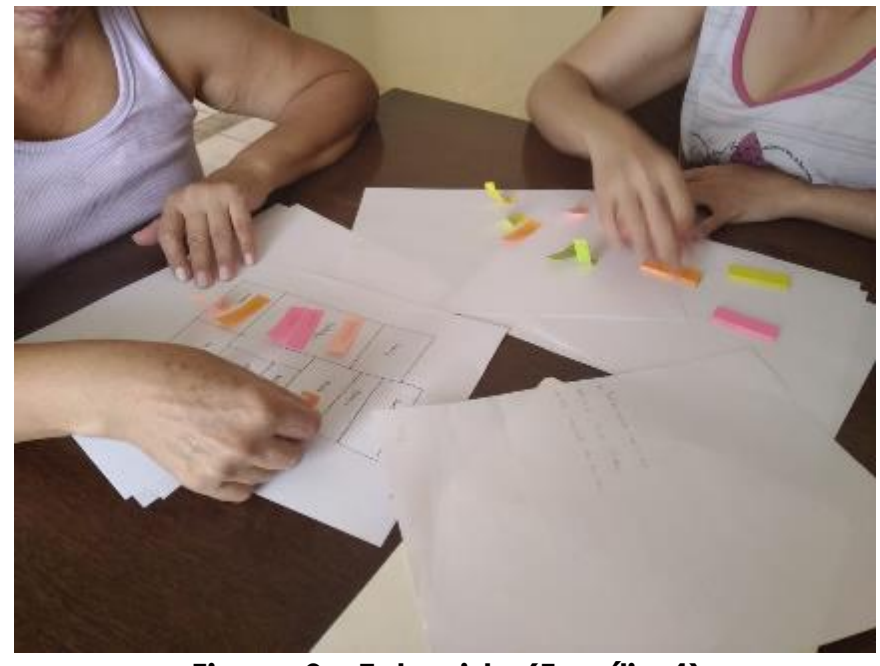

Figura 9 - Entrevista (Família 4)

Fonte: Os autores (2018) 


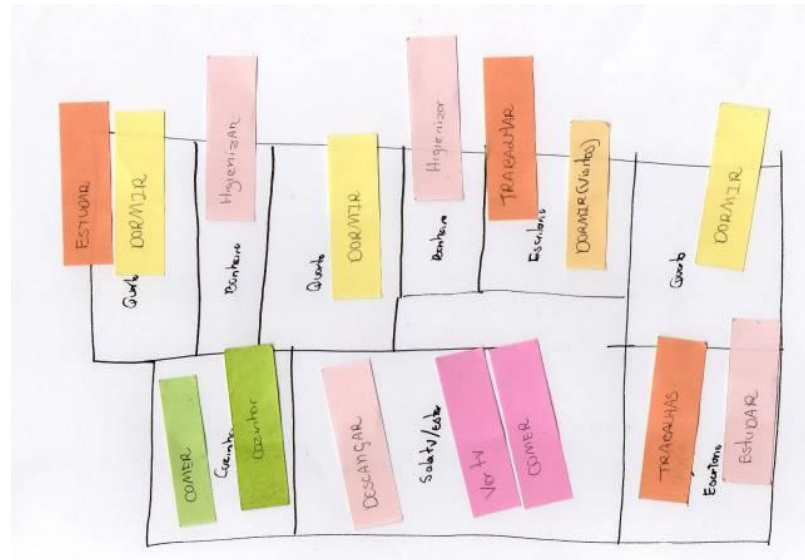

Figura 10 - Exercício Projeto do Cliente + D.G (Família 4)

Fontes: Os autores (2018)

Na etapa de Elaboração das opções de projeto foi possível concluir que fazer as plantas no AutoCAD e trata-las a mão livre não trouxe prejuízo para o processo, pois os usuários ainda se identificaram com a representação e continuaram interagindo com os desenhos. A apresentação de volumetria utilizando software de maquetes eletrônicas 3D se mostrou mais eficiente, se comparada a perspectivas a mão livre, pois proporcionou um melhor entendimento do projeto. Ainda assim foi necessário utilizar o local que iria ser reformado ou construído como suporte para as apresentações, pois levando em consideração que são pessoas que não possuem conhecimento técnico na área, utilizar esse recurso permitiu que elas compreendessem melhor os projetos.

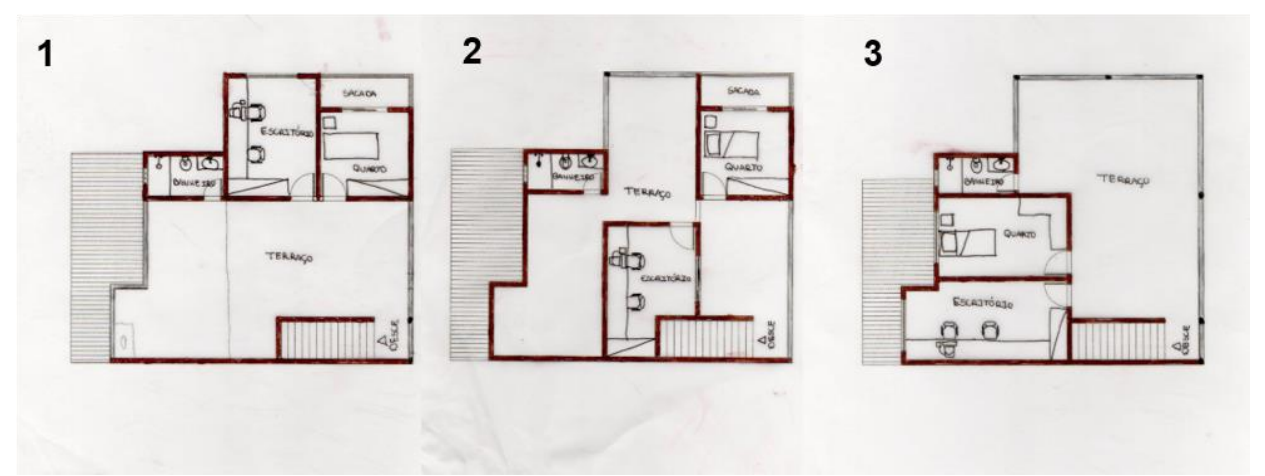

Figura 11 - Opções de projeto (Família 5)

Fonte: Os autores (2018)

Por último, na etapa do Manual de Instrução, foi possível perceber que elaborar plantas separadas por temas e etapas de construção foi eficiente, pois evita o acúmulo de informações em um mesmo desenho, e facilita a compreensão da mão-de-obra durante a execução. Além disso a utilização de perspectivas, substituindo os cortes e as elevações, foi eficiente apenas para demandas de reformas, no caso de construções novas e algumas ampliações se faz necessário a utilização de cortes e elevações. Dessa forma, cabe ao profissional avaliar qual o tipo de representação (dentre essas descritas) consegue transmitir de forma mais clara os elementos necessários para a execução da obra. 


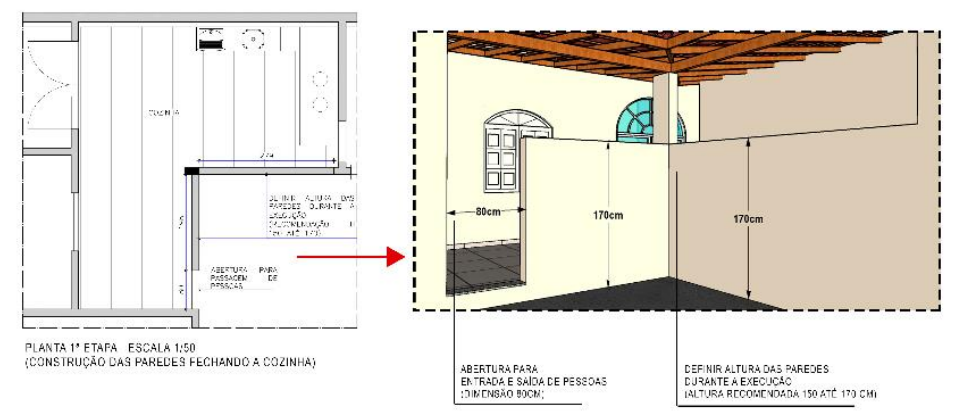

Figura 12 - Manual de Instrução - prancha $1^{a}$ etapa da obra (Família 4) Fonte: Os autores (2018)

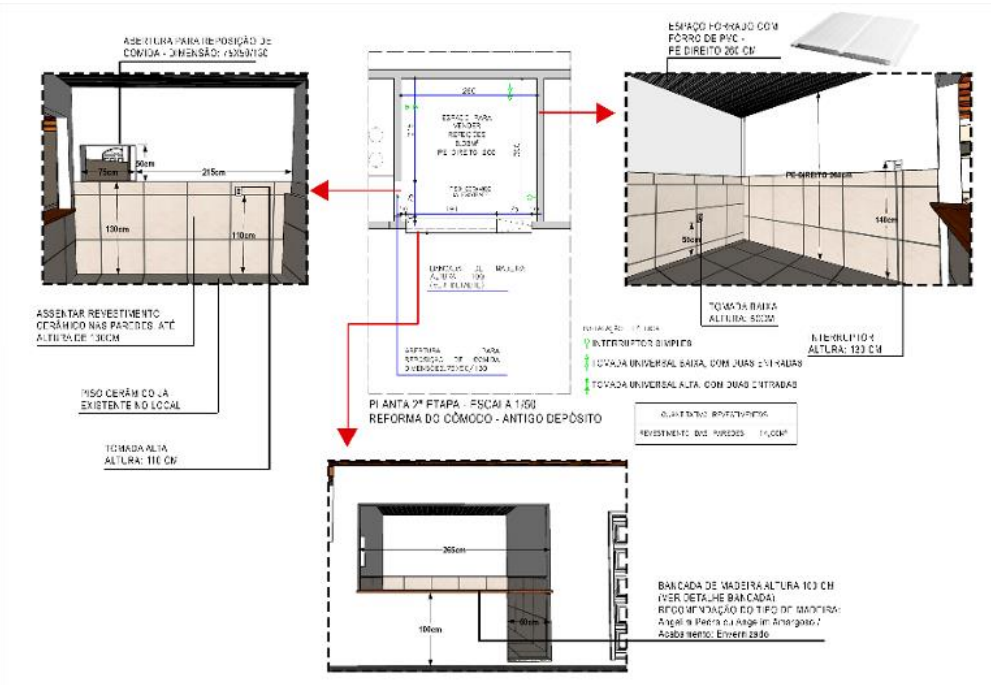

Figura 13 - Manual de Instrução - prancha $2^{a}$ etapa da obra (Família 4) Fonte: Os autores (2018)

Se comparado a prática de arquitetura convencional, o método possibilitou uma maior interação entre o arquiteto e os usuários. Como os clientes tiveram participação ativa durante todo o processo de elaboração dos projetos, as demandas levantadas nas primeiras etapas não foram negligenciadas. Os cinco atendimentos realizados permitiram o aperfeiçoamento do método, para que ele possa auxiliar os profissionais de arquitetura no atendimento às demandas populares da RMVA.

\section{CONSIDERAÇÕES FINAIS}

Mais do que realizar o projeto arquitetônico, o intuito desse estudo foi extrair informações do processo projetual e da relação entre o arquiteto e as demandas populares. Portanto, os projetos realizados serviram como um meio para a construção de um método, que poderá orientar profissionais de arquitetura no desenvolvimento de projeto para esse público na RMVA. Dessa forma, espera-se tornar a prática de arquitetura um pouco mais acessível e 
mais próxima da realidade vivida pelas demandas populares, que estão habituadas a realizar construções sem projeto e sem o auxílio de um profissional especializado. Se faz necessário em estudos futuros avaliar a utilização desse método em escritórios de arquitetura, para que seja possível continuar analisando a sua eficiência no atendimento ao público, e verificar a sua viabilidade econômica.

Quanto as questões relativas à ética na pesquisa, durante a coleta de dados, todos os riscos e desconfortos envolvidos na pesquisa foram apresentados previamente aos participantes, sendo autorizado o registro, escrito e gráfico das informações necessárias, para serem utilizadas integralmente ou em partes, na realização do artigo. Os pesquisadores trataram as identidades com padrões profissionais de sigilo e confidencialidade, atendendo à legislação brasileira, em especial à Resolução 466/2012 do Conselho Nacional de Saúde.

\section{REFERÊNCIAS}

AYER, Flávia. (2018, 08 de janeiro). Desemprego no Brasil impõe novos hábitos de consumo para a classe C. Estado de Minas, Minas Gerais. Disponível em: <https://www.em.com.br/app/noticia/economia/2018/01/08/internas_econom ia,929350/desemprego-no-brasil-impoe-novos-habitos-de-consumo-para-aclasse-c.shtml>. Acesso em: 04 de abril. 2018

CAU (Brasil). Anuário de Arquitetura e Urbanismo traz dados inéditos sobre a profissão. (2017, 07 de outubro). Conselho de Arquitetura e Urbanismo do Brasil. Disponível em: <http://www.caubr.gov.br/anuario-de-arquitetura-e-urbanismotraz-dados-ineditos-sobre-profissao/> Acesso em: 18 de fev. 2018

. O maior diagnóstico sobre arquitetura e urbanismo já feito no

Brasil. (2015). Conselho de Arquitetura e Urbanismo do Brasil. Disponível em: <http://www.caubr.gov.br/pesquisa2015/> Acesso em: 18 de fev. 2018.

KAPP, Silke; NOGUEIRA, Priscilla; BALTAZAR, Ana Paula. Arquiteto sempre tem conceito, esse é o problema. IV Seminário Projetar, São Paulo. Projeto como investigação: ensino, pesquisa e prática. 2009. Rio de Janeiro, AU-UPM.

NOGUEIRA, Priscilla. Discutindo a lógica da autoprodução de moradias. Revista Oculum Ensaios, Campinas: Revista do programa de pós-graduação em urbanismo, 10(1), 57-72, janeiro-junho 2013.

Práticas de Arquitetura para demandas populares - A experiência dos Arquitetos da Família. Dissertação de mestrado - Universidade Federal de Minas Gerais. Belo Horizonte, 2010.

SA, Lorrainy Cristina Lage; ÁVILA, Vinícius Martins. Práticas de arquitetura para Demandas Populares da Região Metropolitana do Vale do Aço. In: Encontro da Associação Nacional de Pesquisa e Pós-Graduação em Arquitetura e Urbanismo, 5., 2018, Salvador. Anais... Salvador: Universidade Federal da Bahia, Faculdade de Arquitetura de Urbanismo, 2018. v. 1, p. 1118 - 1142. 